Article

\title{
Influence between COVID-19 Impacts and Project Stakeholders in Chilean Construction Projects
}

\author{
Felipe Araya ${ }^{1}(\mathbb{D})$ and Leonardo Sierra ${ }^{2, *}$ (D) \\ 1 Departamento de Obras Civiles, Universidad Técnica Federico Santa Maria, Valparaíso 2390123, Chile; \\ felipe.araya@usm.cl \\ 2 Departamento de Obras Civiles, Universidad de La Frontera, Temuco 4811230, Chile \\ * Correspondence: leonardo.sierra@ufrontera.cl
}

Citation: Araya, F.; Sierra, L. Influence between COVID-19 Impacts and Project Stakeholders in Chilean Construction Projects. Sustainability 2021, 13, 10082. https://doi.org/ $10.3390 /$ su131810082

Academic Editor: Dorota Kuchta

Received: 29 June 2021

Accepted: 2 September 2021

Published: 9 September 2021

Publisher's Note: MDPI stays neutral with regard to jurisdictional claims in published maps and institutional affiliations.

Copyright: (c) 2021 by the authors. Licensee MDPI, Basel, Switzerland. This article is an open access article distributed under the terms and conditions of the Creative Commons Attribution (CC BY) license (https:// creativecommons.org/licenses/by/ $4.0 /)$.

\begin{abstract}
The construction sector has been heavily impacted by COVID-19 due to the restricted conditions required by construction projects to perform physical activities. Given this context, it is of interest for the industry to identify the impacts that COVID-19 has had on the development of construction projects. However, little is known regarding how the impacts of COVID-19 have affected multiple stakeholders in construction projects and whether there is some interaction among such impacts. This study aims to explore the impacts of COVID-19 and their influence among different construction stakeholders (i.e., engineers and managers, workers, suppliers). This study was enabled by 40 semi-structured interviews that were performed with stakeholders in construction projects in Chile. Content analysis from the interviews led to the identification of categories of impacts and stakeholders, to the development of a cognitive map of the impacts, and to the application of correspondence analysis. Fifteen categories of impacts were identified, and six construction stakeholders were identified as having been impacted by COVID-19. Identifying the causes and effects of the impacts felt by multiple stakeholders revealed that these impacts interacted among each other. Understanding the impacts of COVID-19 on construction stakeholders may facilitate the development of effective mitigation strategies to reduce COVID-19 impacts on the construction sector.
\end{abstract}

Keywords: construction; COVID-19; causes; impacts; qualitative content analysis; correspondence analysis

\section{Introduction}

The implementation of social distancing policies in response to the COVID-19 pandemic has modified how our society works (e.g., [1-3]). Multiple sectors have shifted from physical to virtual environments to keep functioning, such as schools and universities; however, there are sectors where it is impossible to replace physical activities with virtual tasks, such as the construction industry [4,5]. The COVID-19 pandemic across the world has heavily disrupted the construction industry in multiple ways, such as limiting the number of workers allowed on construction sites, delaying projects' execution, adding financial stress to construction companies, and legal challenges related to the interpretation of contractual clauses, such as force majeure [6-10]. Furthermore, given the relevance that the construction sector has for the economic recovery of nations, it is of paramount importance to understand the impacts from COVID-19 on the construction industry $[11,12]$. Given this context, studies have explored the impacts of COVID-19 and have focused on specific challenges for construction projects due to the pandemic. For instance, Ref. [7] studied the force majeure clause in public-private partnership projects during the COVID-19 pandemic; Ref. [13] discussed the need for suppliers to offer alternative sources of materials and equipment to minimize delays given the pandemic context; and [4] explored the spread of COVID-19 among construction workers using a simulation approach.

Of note, recent studies have explored the impacts and challenges that COVID-19 has had on construction, which provides a more integrative approach to study the influence 
of COVID-19 on the sector (e.g., [6,11,14]). For instance, Ref. [14] identified multiple impacts, efforts to manage such impacts, and new opportunities for the industry due to the need to encourage tools that facilitate working remotely. Ref. [6] identified multiple challenges regarding COVID-19, such as the limited information about COVID-19, shortage of personal protective equipment, and complying with social distancing policies. Similarly, Ref. [11] studied the impacts reported in the existing literature and, of interest, the authors suggested that the impacts of COVID-19 in the construction sector could be organized into four categories: workforce issues, project and workplace issues, procurement and supply chain issues, and contractual issues, thus emphasizing the multidimensionality that the impacts that COVID-19 had on the construction sector [11]. Yet, limited studies exist that are supported by actual data collected from workers, companies, or other construction projects' stakeholders. Although this limitation in the literature is understandable, as collecting data in construction sites is challenging during the current pandemic context, collecting data from the field might shed light onto otherwise undetected impacts from COVID-19 on construction projects. Additionally, the existing literature has studied the impacts of COVID-19 on the construction sector as independent impacts and has not explored the possibility that these impacts might interact among multiple construction stakeholders. From a practical standpoint, understanding the impacts that COVID-19 has had on construction projects may facilitate the development of future plans and strategies by authorities to minimize the consequences of the pandemic. Moreover, if the impacts can be identified by construction stakeholders, the strategies developed by authorities can be tailored to the needs of each construction stakeholder affected by the pandemic. In so doing, strategies to fight the pandemic in the construction sector may be more efficient.

Given this context, this study qualitatively analyzed the responses to interviews with construction stakeholders working on construction projects during the COVID-19 pandemic. Enabled by these analyses, this study aims to achieve three objectives: (1) identify the impacts of COVID-19 on the construction sector among multiple stakeholders, namely companies, administration and design team, construction engineers and managers, workers, subcontractors and suppliers; (2) how the cause and effect of such impacts vary among the multiple stakeholders, and (3) identify whether there is an association between impacts due to COVID-19 and construction stakeholders.

\section{Research Background}

Since the COVID-19 pandemic started, multiple studies have explored the impacts of the pandemic on the construction industry (e.g., [11,14-17]). Given the multiple stakeholders involved during construction projects, a large variety of impacts from COVID-19 have been identified affecting different construction stakeholders (e.g., managers, workers), as such in this literature review, it is discussed the impacts from COVID-19 organized by construction stakeholder, namely company, project administration team, construction engineers and managers, workers, and subcontractors and suppliers. This organization of construction stakeholders is used as it is consistent with the existing literature [18-20].

Authors have identified that the main impact of COVID-19 for construction companies is in the financial dimension. It was discovered that COVID-19 caused additional costs, payment delays, and loss of revenue for construction companies [14,21]. Furthermore, Ref. [22] found that the financial impact of companies was an impact from COVID-19. Ref. [22] went further and suggested that financial impacts might have been caused due by the deterioration of the government investments and due to the suspension of projects. Financial impacts on construction companies have also been identified to reduce contractors' income due to project delays and suspension and the additional projects' costs due to protocols and requirements to comply with health strategies against COVID-19 [21]. More recently, Ref. [23] explored the impacts of COVID-19 on construction projects and found that at the company level, the main impact was the financial solvency of the company. Of note, the challenge of financial solvency at the construction company level was found to refer to present and future financial solvency as well. 
Concerning the impacts for the project administration team, the existing literature has been focused on contractual issues and the higher complexity to manage construction projects due to COVID-19. Regarding contractual challenges, Refs. $[7,14]$ identified that the use of force majeure clauses might increase the disputes, claims, and litigations on construction projects during the pandemic context. In terms of facing a higher complexity to manage construction projects, authors have suggested that such a higher complexity comes from managing risks and implementing safety guidelines to minimize the spread of COVID-19 [5,24], limited productivity on construction operations [14,21], and the shortage of skilled workers and materials to develop construction projects [14,25]. Interestingly, some authors have also identified positive impacts on construction projects due to the COVID-19 pandemic. For instance, Ref. [26] discussed that construction projects of transportation infrastructure had been completed quicker than expected due to limited traffic. Additionally, Ref. [27] discussed that the current pandemic might be an excellent opportunity to implement digital technologies to develop construction projects.

Regarding the impacts of COVID-19 on construction engineers and managers, the existing literature has been mostly focused on identifying challenges that construction engineers and managers have faced during the current pandemic, including safety risks and thus the need to implement safety protocols (e.g., $[6,24])$, management of construction delays, shortages of resources (e.g., [11]), and implementation of technologies that facilitate working remotely (e.g., [11,17]). Ref. [24] focused on the vital role of managers in construction projects to promote initiatives and implement strategies to reduce the spread of COVID-19 among workers. It was suggested that safety strategies to deal with COVID-19 might be more effective if integrated with pre-existing safety processes [24]. Similarly, Ref. [6] found that challenges for managers and engineers in controlling COVID-19 have included shortages of the personal protection equipment supply, complying with social distancing mandates on construction sites, and transportation of workers between the workplace and their homes. Additional challenges that have been identified disrupting the work of engineers and managers include shortage of skilled workers and materials, deciding to continue or halting a construction project under development due to financial reasons, and having the capacity to implement technologies that facilitate working remotely, such as BIM or BIM360 [11].

Regarding the impacts of COVID-19 on construction workers, most of the existing studies have focused on health and safety issues $[6,15,17,27,28]$. Ref. [27] found that impacts on construction workers include concern about being exposed to the virus at work and applying social distancing policies to minimize such exposure. Similarly, Ref. [17] explored the knowledge, attitudes, and practices of construction practitioners toward COVID-19. Ref. [17] found that construction workers were well-informed about COVID19 and that they tended to take preventive actions to minimize the spread of COVID19 , such as wearing face masks and keeping the social distance at work; however, the authors emphasized that, for preventive actions to be effective, these must be permanently reinforced among construction workers. More recently, Ref. [15] explored the impacts of working from home during the current pandemic in terms of the health and well-being of construction workers. The authors emphasized the need to consider work-life balance when designing and scheduling teleworking for construction workers to maximize the well-being of workers.

Concerning the impacts of COVID-19 on construction suppliers, existing studies have emphasized that one of the main challenges has been the material shortage and lack of supplies for construction projects that lead to project delays [11,14,22]. Ref. [14] discussed the challenge of projects that need supplies from international suppliers given the closed border policies that the majority of countries have implemented due to COVID-19. Similarly, Ref. [29] identified that a measure to minimize the impact on the construction supply chain is to identify at-risk suppliers that might not be replaced. Ultimately, regarding impacts on owners and public agencies, the literature indicates that workforce reduction due to the 
pandemic context may limit their capacity to develop new construction projects (owners) and oversee permits for construction projects in the case of agencies [11].

In summary, the recent literature has identified that the impacts of COVID-19 on the construction industry encompass multiple stakeholders (see Table 1); nonetheless, limited studies exist that explore the interactions of such impacts among multiple construction stakeholders. Furthermore, understanding the impacts of COVID-19 on construction projects and the stakeholders affected by them may assist and facilitate the development of mitigation strategies to reduce such impacts among construction projects. This existing gap motivates this study on how the impacts of COVID-19 influence multiple stakeholders, and how such impacts may interact among construction stakeholders.

Table 1. Summary of literature review about COVID-19 impacts.

\begin{tabular}{|c|c|}
\hline Stakeholder Categories & Studies Identifying COVID-19 Impacts \\
\hline Construction workers & $\begin{array}{l}\text { Impacts on the health and safety of workers, such as exposure } \\
\text { to COVID-19 }[6,15,17,27]\end{array}$ \\
\hline Project administration team & $\begin{array}{c}\text { Impacts on contractual issues, such as force majeure clause, } \\
\text { and higher complexity to manage construction projects; for } \\
\text { instance, lower productivity, limited workforce, and safety } \\
\text { protocols }[5-7,11,14,17,21,24-27]\end{array}$ \\
\hline Company & $\begin{array}{l}\text { Financial impacts due to additional costs, payment delays, } \\
\text { and loss of revenue during the pandemic }[14,21-23]\end{array}$ \\
\hline Suppliers and Subcontractors & $\begin{array}{l}\text { The material shortage and lack of supplies for construction } \\
\text { projects }[11,14,22]\end{array}$ \\
\hline Owner/Developer & Workforce reduction due to pandemic context [11] \\
\hline Public agencies & $\begin{array}{l}\text { Workforce reduction limit capacity to oversee permits for } \\
\text { projects under development [11] }\end{array}$ \\
\hline
\end{tabular}

\section{Materials and Methods}

In this section, the rationale behind the methods used to achieve the objectives of this study is explained. The qualitative content analysis (QCA) applied to the interviews identify categories of impacts and stakeholders affected by such impacts, which is objective number one. From a QCA, a cognitive map of the impacts is developed which facilitates an understanding of the impacts of COVID-19 among construction stakeholders-i.e., objective number two. Finally, the application of correspondence analysis determines the states of association among impacts due to COVID-19 and construction stakeholders, which is objective number three. The following subsections describe in detail the data and methods used in this study.

\subsection{Data Collection}

Data for this study was collected through 40 semi-structured interviews with construction stakeholders-i.e., workers, engineers, managers-working on construction related jobs during the current pandemic context. Convenience and snowball sampling were used to reach interviewees as this study is exploratory in nature. It is important to note, this study did not perform a random sampling. Snowball sampling was chosen to target respondents that met two practical criteria [30,31]. Namely, having considerable experience in the construction industry, and participating on a construction project during current COVID-19 pandemic from the position they hold in their organization. Information about interviewees is shown in Table 2, the average number of years of experience of the interviewees was of 12.8 years. 
Table 2. Characteristics of interviewees.

\begin{tabular}{ccc}
\hline Category & Description & Frequency (\%) \\
\hline $\begin{array}{c}\text { Geographic location of } \\
\text { interviewee }\end{array}$ & Central region & $24(60.0 \%)$ \\
Gender & Southern region & $16(40.0 \%)$ \\
\hline & Male & $35(87.5 \%)$ \\
Position in Project & Field level & $5(12.5 \%)$ \\
& (e.g., construction engineer, safety engineer) & $20(50.0 \%)$ \\
& Management level & $13(32.5 \%)$ \\
& (e.g., manager, administrator) & $7(17.5 \%)$ \\
\hline \multirow{2}{*}{ Experience in Industry } & $0-5$ years & $8(20.0 \%)$ \\
& $6-10$ years & $13(32.5 \%)$ \\
& $11-15$ years & $8(20.0 \%)$ \\
& $16-20$ years & $3(7.5 \%)$ \\
& $21-25$ years & $3(7.5 \%)$ \\
& $26-30$ years & $2(5.0 \%)$ \\
& $31-35$ years & $3(7.5 \%)$ \\
\hline
\end{tabular}

The sample of this study is within the range of sample size reported in recent literature exploring the issue of COVID-19 on the construction sector using qualitative approaches (e.g., $n=12$, [5]; $n=14,[16] ; n=19$, [6]; $n=34$, [14]). The sampling of interviews was done until the saturation point was reached, which is when an additional interview provided limited additional information from the already collected information [32].

Semi-structured interviews were conducted using a combination of online and inperson interviews. In-person interviews were performed by visiting multiple construction sites, and when visiting the construction sites, all the safety protocols established by the construction project were followed to protect the safety of researchers and interviewees. Online interviews were performed when interviewees were not available to meet on the construction sites. Interviews were conducted between May and November of 2020 and encompassed construction projects located in the central and southern region of Chile. Interviews had an extension varying between 40 to $60 \mathrm{~min}$. The questions from the interviews were developed to identify impacts faced by construction stakeholders. Questions were open-ended to promote discussion about respondents' opinions and experiences during the current pandemic context. Examples of questions include the following:

- Please describe the impacts that the COVID-19 has had on the project that you are currently working?

- Please describe the construction processes and stakeholders that have been affected by COVID-19?

\subsection{Qualitative Content Analysis and Correspondence Analysis}

Given the novel and unexpected nature of the spread of COVID-19 in our society, there is limited understanding about the impacts of COVID-19 on the construction sector. As such, this study adopted an exploratory research approach based on qualitative analysis to explore the impacts of COVID-19 on multiple construction stakeholders. The adoption of qualitative research methods given the existing limitations due to the COVID-19 pandemic has been suggested by multiple authors (e.g., [6,33]). Qualitative methods provide a high level of flexibility to understand emergent topics and leverage knowledge from people dealing with these topics; thus, providing an ideal tool to study the impacts of COVID-19 on construction projects affecting multiple stakeholders. Emergent coding was used to identify themes and ideas within the data transcribed from the interviews [34]. Furthermore, multiple studies have already applied qualitative research methods to explore the influence of COVID-19 in the construction industry, and as such, emphasizing the value 
of applying these research methods to better understand the influence of the current pandemic context in the construction sector (e.g., [6,16,29]).

Specifically, this process was conducted according to the six-steps highlighted in $[33,35]$ for a qualitative content analysis: Familiarization, Coding, Generating themes, Reviewing themes, Defining and naming themes, Writing up. The stage of familiarization involves becoming familiarized with the data by reading/listening and reviewing it to have a better understanding of the data that will be further analyzed and coded. In this line, all interviews were transcribed and iteratively codded into multiple impacts and categories using content analysis. This process ensures replicability and validity of the results obtained [36]. It is important to note that identified categories of impacts due to COVID-19 emerged from the analysis of interviews, and the categories identified were not pre-defined by the research team [37]. First, statements were coded as an impact on construction projects due to COVID-19 and as a stakeholder affected by such impact. In addition, a cognitive map emerges from the discourse of the interviewees to understand the detail of the relationships between impacts and stakeholders. Registered stakeholders are those directly interviewed or indirectly mentioned in the speech of an interview. The coding and map were completed by two researchers with excerpts reviewed by all researchers. Responses were coded first based on the impacts that COVID-19 has had on the construction industry. Then, the categories of impacts and stakeholders emerged from the results of an inductive process, that is, the categories are defined by grouping-relevant annotations and with conceptual affinity [38,39] (Tables 3 and 4). Conceptual affinity means that the multiple responses coded were grouped into the different categories that emerged during the coding process by their level of similarity. Of note, the authors have previously applied the inductive coding process using qualitative analysis (e.g., $[23,38]$ ). The cognitive map is adjusted in consistency with the categorization of impacts and stakeholders. (Figure 1). From the cognitive map, researchers identify the cause and effect corresponding to each impact category and stakeholder affected. The frequencies in which each impact was identified as a cause or effect are counted in a contingency table (Table 5). This analysis allows the quantification of the study of the dimensions not visible that is applied in the correspondence analysis.

Table 3. Categories of impacts of COVID-19 on construction projects.

\begin{tabular}{|c|c|c|}
\hline Number & Impact Categories & Description of Impacts \\
\hline 1 & $\begin{array}{l}\text { Employment suspension and } \\
\text { unemployment }\end{array}$ & $\begin{array}{c}\text { Construction workers lose their jobs and income generating uncertainty } \\
\text { on their work stability due to unemployment, job suspension, and } \\
\text { long-term inactivity }\end{array}$ \\
\hline 2 & Quarantine and restrictions & $\begin{array}{l}\text { Quarantine policies and restrictions by public authorities limit the } \\
\text { capacity of workers to keep working on the construction sector and of } \\
\text { companies to supply construction materials and other resources }\end{array}$ \\
\hline 3 & Technical performance of workers & $\begin{array}{c}\text { Disruptions on the performance of workers due to the pandemic context. } \\
\text { For instance, reduction in the number of workers, less supervision, } \\
\text { reduction of working hours and limitation in the use of spaces, and } \\
\text { coordination/communication problems }\end{array}$ \\
\hline 4 & Distribution and stock of Materials & Shortage and delay of construction materials on the construction site \\
\hline 5 & Public management & $\begin{array}{l}\text { Problems on construction projects due to delays on public agencies, for } \\
\text { instance delivering permits to construction projects }\end{array}$ \\
\hline 6 & $\begin{array}{l}\text { Difficulties of workers to mobilize } \\
\text { to work }\end{array}$ & $\begin{array}{l}\text { Public policies against COVID-19 limit the mobility of workers and } \\
\text { workers cannot travel to construction sites, and limitations to use public } \\
\text { transportation }\end{array}$ \\
\hline 7 & Project stops and delays & $\begin{array}{l}\text { Construction projects are stopped or delayed due to pandemic context } \\
\text { Safety culture, contagion risk, ignorance of the COVID protocol, } \\
\text { investment in supplies and personnel protection infrastructures, greater }\end{array}$ \\
\hline 8 & Concerns about health and safety & $\begin{array}{l}\text { attention to safety and health on job performance, greater protection in } \\
\text { activities and access to the work, uncertainty of the health status of the } \\
\text { staff, information and health education of staff, reduced self-care, } \\
\text { random and unplanned application of PCR-COVID tests. }\end{array}$ \\
\hline 9 & $\begin{array}{l}\text { Non-economic family problems of } \\
\text { workers }\end{array}$ & $\begin{array}{l}\text { Construction workers having problems at the family level due to the } \\
\text { pandemic context (family contagion), such as delays in the arrival to their } \\
\text { jobs, workers missing their jobs, and losing their concentration at work }\end{array}$ \\
\hline
\end{tabular}


Table 3. Cont

\begin{tabular}{|c|c|c|}
\hline Number & Impact Categories & Description of Impacts \\
\hline 10 & Productivity & $\begin{array}{c}\text { Reduction in the productivity of construction workers due to pandemic } \\
\text { conditions }\end{array}$ \\
\hline 11 & Safety and health protocols & $\begin{array}{l}\text { Construction activities require extra attention regarding safety aspects } \\
\text { that in many cases delay the execution of such activities }\end{array}$ \\
\hline 12 & Industry resiliency & $\begin{array}{l}\text { Construction industry keeps functioning despite limited resources are } \\
\text { available such as materials, human resources, and money }\end{array}$ \\
\hline 13 & Mental health & $\begin{array}{l}\text { Mental health of workers is affected by the pandemic context and in } \\
\text { many cases reduces productivity and affects the work environment }\end{array}$ \\
\hline 14 & Present and Future Financial solvency & $\begin{array}{l}\text { Disruption on construction companies due to limited new projects, } \\
\text { economic losses during the pandemic, absence of new projects in the } \\
\text { short term, reinvestment in the work due to prolonged stoppages, } \\
\text { decrease or loss of family income, higher direct/indirect costs in the } \\
\text { project, bankruptcies of subcontractors, redistribution of funds from } \\
\text { public works projects, delay in the payment of the progress of the works, } \\
\text { reduction of the labor supply, diversification of the sources of income of } \\
\text { the workforce, late economic support from the Government, difficulty in } \\
\text { accessing bank loans }\end{array}$ \\
\hline 15 & Use of existing local suppliers & $\begin{array}{l}\text { Alternative materials obtained from local suppliers must be used to keep } \\
\text { construction projects going on. Additionally, use of substitute materials, } \\
\text { and use of stock of materials from other projects. }\end{array}$ \\
\hline
\end{tabular}

Table 4. Stakeholders affected due to impacts from COVID-19 on construction projects.

\begin{tabular}{|c|c|c|}
\hline Number & Stakeholder Categories & Description of Stakeholders \\
\hline 1 & Construction workers & Construction workers and professionals on the field \\
\hline 2 & Project team members & Engineers and managers in charge of managing a construction project \\
\hline 3 & Company & $\begin{array}{c}\text { Representative of the construction company developing a construction } \\
\text { projects such as a company manager. }\end{array}$ \\
\hline 4 & Suppliers and Subcontractors & Subcontractor companies, material, and equipment suppliers \\
\hline 5 & Owner/Developer & Representatives of construction project owners and developers \\
\hline 6 & Public agencies & $\begin{array}{l}\text { Representatives of public agencies that provide permits or approvals } \\
\text { during the development of construction projects such as a field inspector in } \\
\text { charge of permits approval }\end{array}$ \\
\hline
\end{tabular}

Table 5. Cause and effect of impacts and stakeholder affected categories.

\begin{tabular}{|c|c|c|c|c|c|c|c|c|c|c|c|c|c|c|c|}
\hline Effects of Impacts & (1) & (2) & (3) & (4) & (5) & (6) & (7) & (8) & (9) & (10) & (11) & (12) & (13) & (14) & (15) \\
\hline Stakeholder category & & & & & & & & & & & & & & & \\
\hline Construction workers & 15 & 1 & 24 & - & - & 7 & - & 23 & - & 5 & - & - & 37 & 23 & - \\
\hline Suppliers and Subcontractors & 2 & - & 1 & 9 & - & - & 4 & - & - & - & - & - & 1 & - & 4 \\
\hline Public agencies & - & - & - & - & - & - & - & - & - & - & - & 4 & - & - & - \\
\hline Project team members & - & - & 27 & - & - & - & 45 & 12 & - & 44 & 1 & 9 & - & 16 & 1 \\
\hline Owner/Developer & - & - & - & - & - & - & - & - & - & - & - & 1 & - & 9 & - \\
\hline Company & - & - & - & - & - & - & - & - & - & - & - & 1 & - & 22 & - \\
\hline
\end{tabular}

\section{Cause of Impacts}

\section{Stakeholder category}

Construction workers

Suppliers and Subcontractors

Public agencies

Project team members

Owner/Developer Company

\begin{tabular}{ccccccccccccccc}
14 & 23 & 32 & - & - & 12 & - & 28 & 3 & - & - & - & 21 & 11 & - \\
2 & - & 2 & 24 & - & - & 2 & - & - & - & - & - & - & 3 & 3 \\
- & 10 & - & - & 5 & 3 & - & 2 & - & - & - & 4 & - & - & - \\
- & - & 20 & - & - & - & 26 & 12 & - & 2 & 35 & 5 & - & 10 & - \\
- & - & - & - & - & - & - & - & - & - & - & 1 & - & 7 & - \\
- & - & - & - & - & - & - & - & - & - & - & 1 & - & 15 & - \\
\hline
\end{tabular}




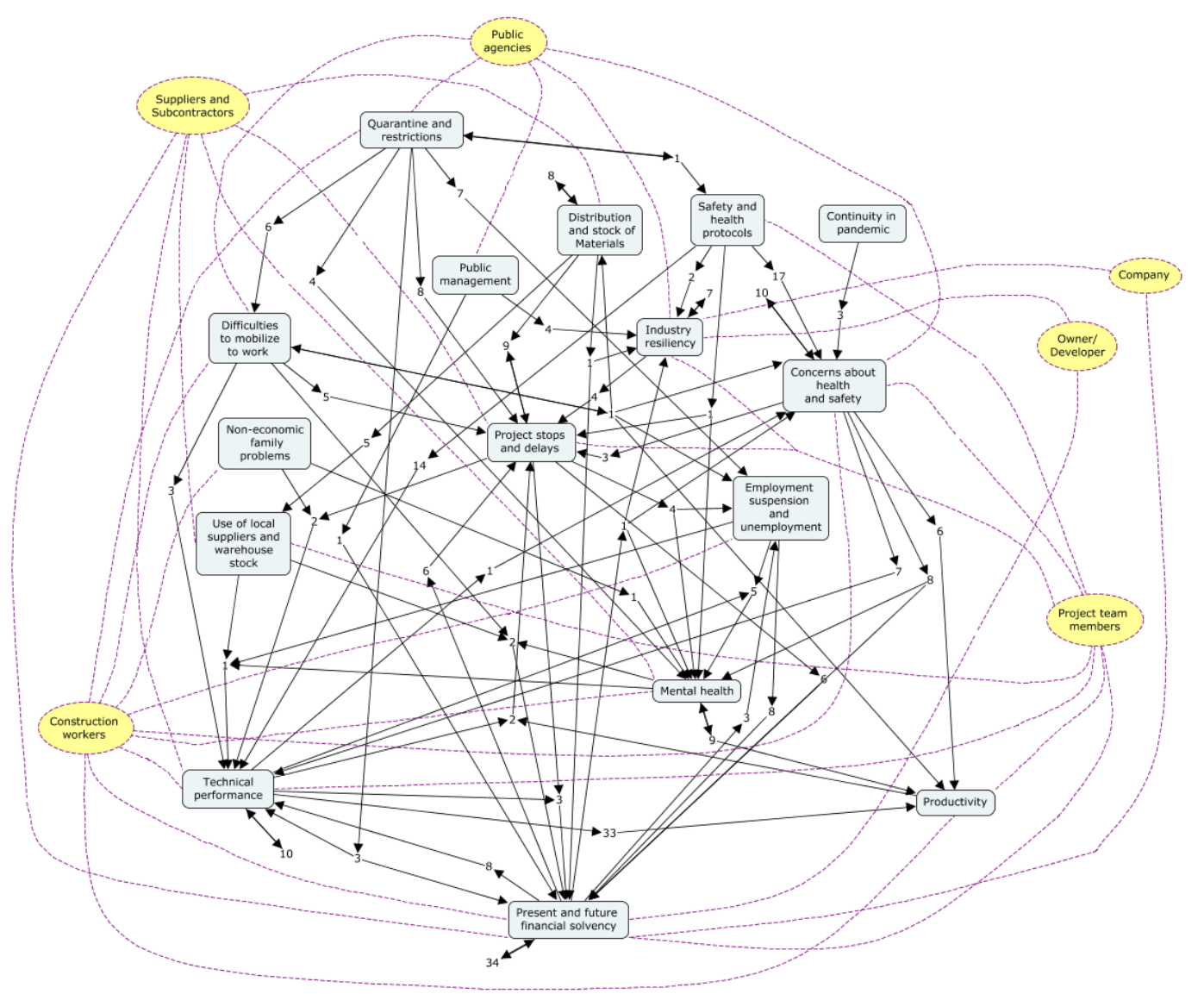

Figure 1. Relationships among impact categories.

Correspondence analysis (CA) is a quantitative data analysis method that offers researchers a visual understanding of relationships/associations between qualitative variables $[40,41]$. Even though CA closely relates to the chi-square statistic, it is not an inferential method for directly testing theory and hypotheses. Instead, CA is a descriptive data reduction technique, similar to principal components analysis. As widely used statistical methods seldom consider relationships between categorical variables, many such relationships/associations go unnoticed in datasets. Although CA is a descriptive method, identification of any such previously unnoticed relationships can lead to future hypothesis testing [42].

The concepts of profile, centroid, chi-square distance, and inertia are essential to understanding CA. A row, or column (of a contingency table) profile provides information on average sets of observations. The points on a correspondence plot reflect the row and column profiles. The centroid, then, is the weighted average of the profiles, which becomes the $(0,0)$ point on the correspondence plot. Profile points appearing close to the centroid on the correspondence plot indicate less variation. Profile points appearing farther away from the centroid indicate more variation. CA uses chi-square distance to measure the distance between points. Though the distance between points suggests in which row and column profiles appear together, the observed distance does not provide an exact measure of the relationship between variables. The inertia, the weighted average of the sum of squared chi-square distance from a given profile to the centroid, describes the variance within a CA. Low inertia indicates profiles clustered closely to the average profile, while high inertia indicates a greater distance between profiles $[42,43]$.

CA has been adequate in exploratory studies of systematic reviews of criteria, empirical studies of stakeholders and of their public responses for the evaluation and planning of infrastructures [44-46]. In this case, correspondence analysis has been used to explore the underline association states among the impact categories and stakeholders. The results 
of the correspondence analysis are shown on two-dimensional plots that represents the association between the stakeholders and the cause and consequences of impacts due to COVID-19 (see Figures 2 and 3). These results are analyzed by observing the groupings of the variables included in the graphics. In general, closer to the cluster of points in the graphics, the stronger the association between them. Other criteria to specify the level of association may include the closeness between the closeness of the column and row dimensions, distance from the origin of the graphic [41].

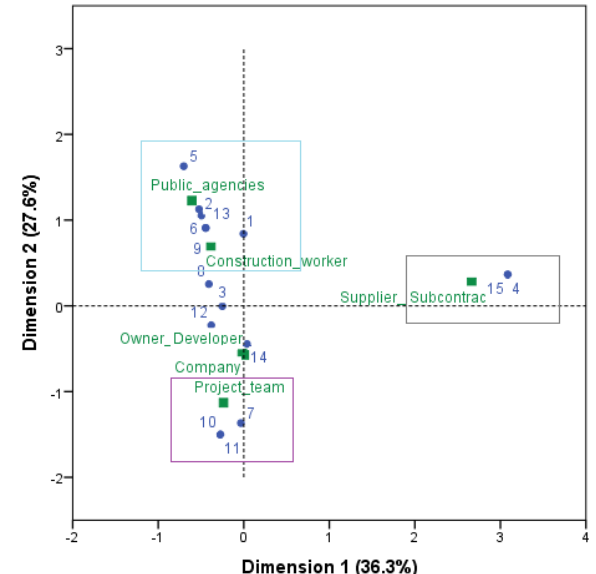

a)

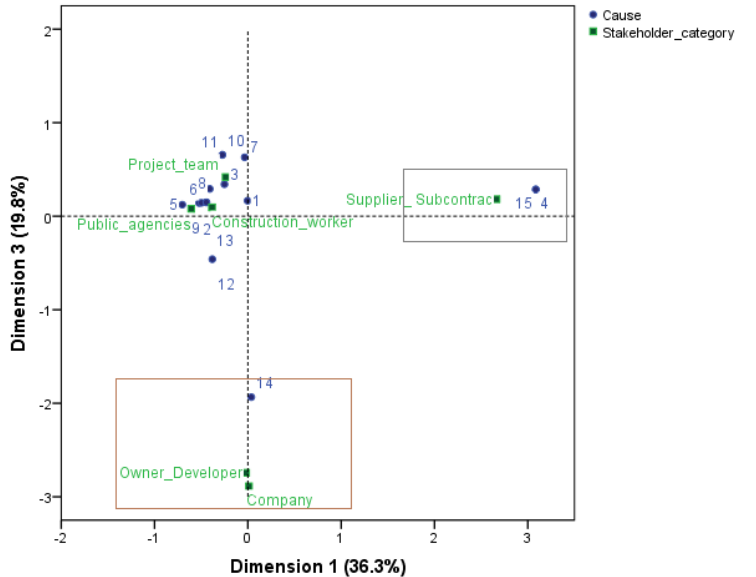

b)

Figure 2. Corresponding analysis plot for causes of COVID-19 impacts on construction. (a) The "Public agencies" cause inconveniences in the "Public management"; (b) The "Supplier and Subcontractor" cause the "Use of local suppliers and warehouse stock".

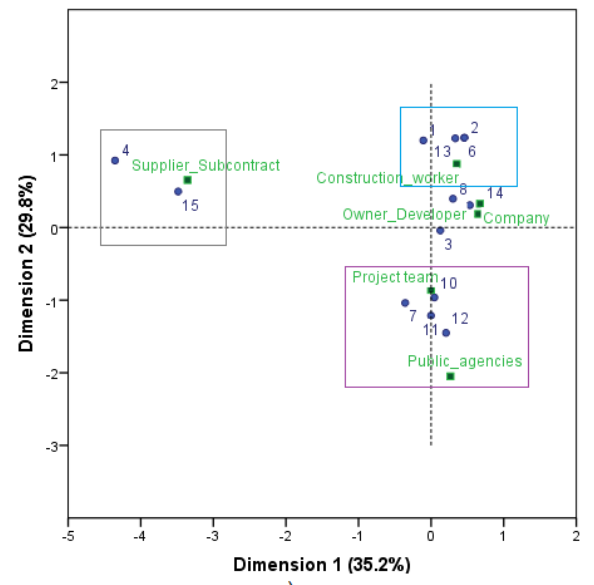

a)

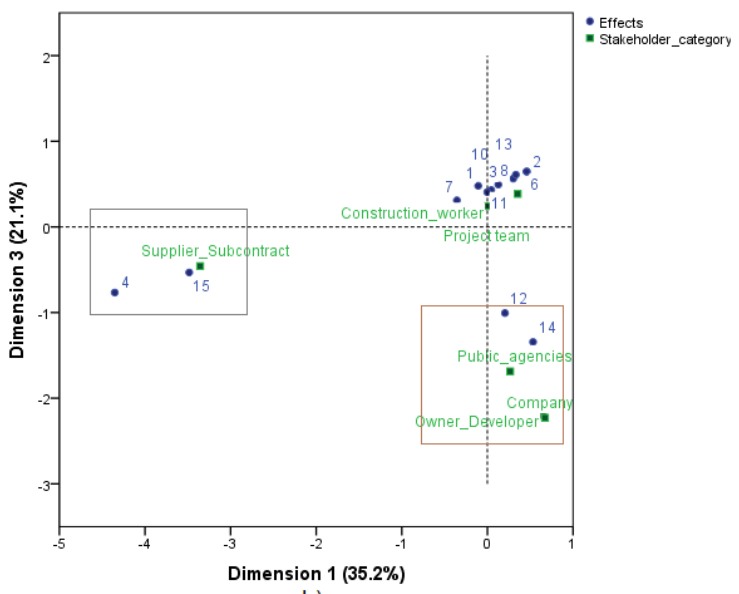

b)

Figure 3. Corresponding analysis plot for effects of COVID-19 impacts on construction. (a) The "Construction worker" are impacted by "Unemployment", "Difficulties to mobilize to work" or "Mental health"; (b) Public agencies are part of the decision-making group and affect the resilience and financial solvency of the industry (e.g., delay in payments for the progress of works or limit the continuity of work).

\subsection{The Context of Chilean Construction during the Pandemic}

After the declaration by the WHO of a global pandemic in March of 2020, the Chilean government implemented lockdown policies for its citizens and for all industries not classified as necessary to deal with the pandemic. The construction sector was recognized as fundamental for the operation of the country during the pandemic context by the government, so it was able to continue developing construction projects. Of note, safety and health protocols were developed to minimize the spread of COVID-19 for all industries that were allowed to continue operating, in the case of the construction industry, safety 
and health protocols were developed by public agencies and the Chilean Chamber of Construction so construction workers were protected against COVID-19 [47]. Examples of these protocols included: forcing workers to wear masks, reduction of the maximum number of workers allowed onsite, provision of private transportation for workers to avoid using public transportation systems.

Despite the protocols and programs to minimize the impacts of COVID-19 on the construction sector, the pandemic has highly impacted the construction industry. Reports developed by the Chilean Chamber of Construction have identified some of the negative impacts that the pandemic context has generated in the Chilean construction industry [38-40]. In terms of the investment levels, it has been estimated that the investment in the construction sector in Chile has decreased approximately 13\% compared with the pre-pandemic status. Similarly, concerning industry jobs, $26 \%$ of construction workers have lost their jobs during the pandemic [48-50].

\subsection{Limitations}

As with any study, this one has limitations. It is acknowledged that this study is focused on the Chilean construction context, which may limit the generalization of findings to the construction sector of other nations. However, it must be recognized that the challenges of COVID-19 on the construction sector are a global issue. Learning about the impacts of COVID-19 and how these may interact among different construction stakeholders may help identifying challenges that local authorities and construction authorities might not be aware of. A second limitation comes from the sample collected in this study, roughly $13 \%$ of interviewees were women, who may appear as a biased sample; nonetheless, this level of participation of women in construction is representative of the Chilean construction sector at the time of preparing this study [51]. Another limitation is that this study was done during the first wave of COVID-19 spread in Chile, and as such, our findings were focused on the first wave, and our results might not be applicable to the situation in which COVID-19 vaccines are being distributed among construction workers. However, this study provides a baseline regarding the impacts of COVID-19 that can be useful for comparisons between the impacts during the different stages of COVID-19. Ultimately, the sample used in this study provided a good understanding about the awareness of the challenges of COVID-19 on the construction sector. However, we must recognize that our sample comes from a subset of Chilean construction stakeholders and some construction stakeholders may have not been included in this exploratory study. To minimize the influence of this limitation, we conducted the interviews until no new information emerged from additional interviews (i.e., reaching the saturation point), and as such, our study can be used to draw valid conclusions.

\section{Results}

Table 3 shows the categories of impacts identified on construction projects due to COVID-19. Fifteen categories of impacts were identified through emergent qualitative analysis, which are aligned with categories of impacts identified in existing literature (e.g., $[5,6,8])$. Table 4 shows the construction stakeholders that were identified to be affected by the impacts due to COVID-19. The six stakeholders identified on this exploratory study were identified as those affected by the previously identified impacts due to COVID-19. Of note, the identified construction stakeholders are aligned with stakeholders identified to be affected by the consequences of COVID-19 in the literature (e.g., [11,17,24]). Notably, the results of Tables 3 and 4 contribute and respond to objective 1 of this study (i.e., identify the impacts of COVID-19 on the construction sector among multiple stakeholders).

Figure 1 shows the stakeholders related to each impact category and how the relationship among the impact categories due to COVID-19 varies. Of note, Figure 1 shows the cause and effect of impacts due to COVID-19 that are illustrated with arrows that enter the boxes (i.e., effects of impacts) and leave the boxes (i.e., cause of impacts). Circles on segmented lines identify the category of stakeholders linked to an impact group. The 
numbers represent the number of times that are linked two impacts between categories, or within a category. Similarly, the two-way arrows represent the internal loops of the impact category. A start arrow that joins others at an intermediate point directs the impact of one category on another (or others) the same number of times in each cause-effect relationship that they share. For example, the category of "Quarantine and Restrictions" impacts three times on the "Technical Performance" and three times on the "Present and future financial solvency". Similarly, "Technical performance" and "Productivity" each impact twice on "Project stops and delays". Or otherwise, the "Distribution and stock of materials" impacts nine times the "Project stops and delays"; at the same time as "Project stops and delays" presents nine additional internal impacts.

Table 5 shows the frequencies of cause and effect of the impacts on construction projects due to COVID-19 for the stakeholders affected by such impacts. These frequencies come from classifying the impacts of COVID-19 on construction projects (Table 3) as a cause and as an effect. Furthermore, causes and effects are paired with the corresponding stakeholder being affected (Table 4). The results from Figure 1 and Table 5 contribute to achieve objective 2 of this study-i.e., how cause and effect of impacts on construction projects due to COVID-19 vary among multiple stakeholders.

Figures 2 and 3 illustrate the results of the corresponding analysis by grouping the causes (Figure 2) and effects (Figure 3) due to COVID-19 impacts on the construction industry with the stakeholder categories. The identification of a cluster among multiple points was subject to the points being close to each other, distant from the origin, and distant from other points, according to Section 2.2. These criteria were used to identify clusters in the plots and understand the association to larger-scale among impact category of COVID-19 and stakeholder categories on construction whether impacts of COVID-19 on construction may be related/non-related with specific stakeholders. According to Section 2.2, Figures 2 and 3 are derived from the data processing of Table 5 translated into scores of underlying dimensions of association. In fact, the CA of the impact categories of causes and effects are represented in statistically significant dimensions according to a Chi-square test with 70 degrees of freedom and 95\% confidence level (Chi-square value is 693,767 and 586,402 , respectively). Three dimensions represent the association in the categories of causes (Figure 2), with $83.8 \%$ of the proportion of accumulated inertia (equivalent to the sum of the proportion explained by each dimension). Likewise, three dimensions represent the association in the categories of effects (Figure 3), with 86.1\% of the proportion of accumulated inertia. The proportion explained by each dimension is presented on the axes of Figures 2 and 3.

In the case of Figure 2, the stakeholder categories that show the greatest inertia (i.e., distanced from the centroid) are "Supplier and Subcontractor", "Public agencies", "Project team", followed by "Construction company". These categories determine four clusters associated with categories of causes. For example, in Figure $2 b$ the "Supplier and Subcontractor" cause the "Use of local suppliers and warehouse stock" (15) and inconveniences in the "Distribution and stock of Materials" (4); or in Figure 2a the "Public agencies" cause inconveniences in the "Public management" (5) and related to "Quarantine and re-strictions" (2) among others. Similarly, in Figure 3, the stakeholder categories with the greatest inertia are "Supplier and subcontractor", "Construction worker", "Project team", and "Public agencies" followed by "Construction Company". Likewise, these categories represent four clusters associated with the effect categories. For example, in Figure 3a the "Construction worker" are impacted (1) "Unemployment", (6) "Difficulties to mobilize to work" or (13) "Mental health"; or the "Project team" is affected by (7) "Project stops and de-lays", the alteration in (10) "Productivity", and (11) "Safety and health protocols", among others.

From the categories that most contribute to the inertia of a dimension, it is possible to infer its meaning. Indeed, in Figures 2 and 3 Dimension 1 is mostly associated with the membership degree of the development of the project. Thus, Dimension 1 represents the greater or lesser affiliation that the stakeholder categories have with the project due to 
COVID 19. This condition is inferred from the inertia of the "Suppliers and subcontractors" on Dimension 1 (Figures 2 and 3). This category is distant from the centroid that concentrates the stakeholders with an invariant relationship around the project. Analogously, Dimension 2 in Figure 2a could determine if the origin of the causes had a greater or lesser degree of dependence on the project. Indeed, according to the inertia of the stakeholders that contribute to Dimension 2, the causes may originate from the management team that develops the project, or on the contrary, from its workers and external regulatory agencies. Meanwhile, Dimension 2 of Figure 3a is mostly associated with the degree of communality of the effects with respect to the project i.e., workers are affected by more individual impacts (e.g., (13) "Mental health") compared to those that have an implication on more members (e.g., (11) "Safety and health protocols" that is related with "Project team" and "Public agencies"). In the same way, Dimension 3 in Figures $2 b$ and $3 b$ can relate the degree of power in decision-making and the causes and effects of COVID-19 derived from these decisions. This hypothesis is inferred from the high inertia of the "Construction companies," "Developers/Owner" contribute to Dimension 3, and the distance and invariability of the rest of the stakeholders and impacts. In fact, the causes derived from decisions in (14) "Financial solvency", or the effects in the (12) "Industry resiliency" are associated with the construction companies and developers/owner.

These results contribute to achieve the objective 3 stated on this study, which is determining whether there is an association between impacts on construction projects due to COVID-19 and construction stakeholders.

\section{Discussion}

Consistent with the recent literature, our results show that COVID-19 has had a variety of impacts on construction projects $[5,14,16,17,52]$. The identified impacts spanned multiple aspects of construction projects, such as financial stability of construction companies, delays in projects due to management practices of public agencies, productivity among workers, the mental health of construction workers, and the distribution and lack of materials among suppliers (see Table 3). Similarly, multiple construction stakeholders were identified to be affected by such impacts, among them construction workers, project members, companies, suppliers and subcontractors, owners, and public agencies (See Table 4). Both findings are aligned with existing literature stating that COVID-19 has placed a variety of impacts on multiple aspects related to construction projects that have affected multiple construction stakeholders (e.g., $[6,10,14])$. Of note, even though studies identifying the impacts of COVID-19 on construction projects have been developed in different regions, such as the United States [14], South Africa [6], China [10], and Chile (i.e., this study), similar impacts on construction projects due to COVID-19 have been reported in such regions. Furthermore, the identification of a variety of impacts disrupting construction projects and multiple stakeholders being affected by such impacts emphasizes that COVID-19 has been highly disruptive to the construction industry. These findings give response to the objective 1 presented in this study.

In addition, to identify the impacts due to COVID-19 on construction projects and stakeholders affected by them, we identified how these impacts varied among multiple stakeholders (see Figure 1 and Table 5). This variation was revealed by identifying cause and effect relationships among the impacts and their corresponding stakeholders. Through qualitative content analysis, it was identified whether an impact was a cause or an effect for another impact, or both, and the corresponding stakeholder related to each cause and affected by each effect (Table 5).

Among the impacts that were identified as a cause of other impacts, those with the highest frequencies were concerns about health and safety and safety and health protocols (i.e., impacts number (8) and (11) respectively on Table 3). Concerns about health and safety caused impacts on the finances of construction companies due to the need to buy personal protective equipment (PPE). Furthermore, when PPE equipment was not available for companies because of the shortage of PPE in the supply chain, construction projects had 
to be stopped, which was reported as an impact by the team of professionals managing construction projects. Similarly, construction workers were also impacted due to concerns about health and safety impacts in the form of being worried about getting infected with COVID-19 and uncertainty about their health status while working on construction projects. Concerning the consequences of safety and health protocols, which is mainly related to the compliance of the new protocols to deal with COVID-19 on construction sites. This impact was identified to have disruptive consequences for the development of construction projects in reducing the number of workers on the field, stopping construction projects, reducing construction workers' hours to work, and extra attention given to safety aspects of construction that may have negatively affected the productivity of workers. These results emphasize that some of the impacts we are observing on construction projects during the current pandemic are due to the protocols to deal with COVID-19 and concerns from workers about getting infected with COVID-19. Our results are aligned with existing studies finding the importance of how the health and safety of construction workers is managed through the pandemic (e.g., [14,16,52]), yet our results also show that workers safety and health may also impact other areas of construction projects, such as the finances of the company.

Regarding the impacts that were identified as an effect of other impacts, the impacts with the highest frequencies were present and future financial solvency, and technical performance (see Table 5). These findings emphasize the financial impact that the pandemic has had on construction projects and the concerns about the financial health of construction companies during the post-pandemic era. Respondents refer to multiple aspects of these impacts. For instance, financial impacts reported by respondents referred to economic losses due to the pandemic context such as limited liquidity of companies, delays in payments to construction companies, and limited new projects to bid on them. Concerning the technical performance, the pandemic has represented a disruption for the performance of construction workers. For example, respondents referred to having problems to do their jobs due to personnel reduction due to social distancing on the construction sites, the hiring of less qualified construction workers, and limited supervision during the construction process.

Of note, tied in the position of the third highest frequency were project stops and delays and productivity (i.e., impacts number (7) and (10) respectively in Table 3). The delaying and halting of construction projects were caused by multiple events highly influenced by the current pandemic context, such as delays in the delivery of materials on the construction sites, construction regions facing quarantine, workers being unable to arrive at construction sites due to mobilization restrictions due to pandemic, and economic loss of construction companies to continue with construction projects. Concerning the productivity as an effect of other impacts, the main reasons for productivity to be affected were related to the hiring of the less qualified workforce due to the pandemic context; facing more restrictions to work on the field due to COVID-19; the number of workers allowed on the field was reduced due to COVID-19 safety protocols, and the additional attention that safety has received during the current pandemic. Of note, our results emphasize that protocols and new onsite conditions due to COVID-19 may represent an inconvenience in terms of keeping the same productivity levels for construction workers. We suggest that the extra attention to safety protocols in construction projects maybe somehow being more restrictive of the conditions that workers often face to do their construction jobs. Our findings are in conversation with other studies in the literature that have identified projects stop, delays and productivity losses as consequences of the current pandemic due to COVID-19 (e.g., [11,14]). Of note, our findings went beyond existing findings and identified causes for those consequences, which contributes to the existing body of knowledge in better understanding the impacts on construction projects due to COVID-19.

Notably, many of the impacts were simultaneously identified as cause and effect by respondents; however, the two that showed the highest frequencies were present and future financial solvency, and technical performance of workers (i.e., impacts number 
(14) and (3) respectively on Table 3). When looking into the present and future financial solvency of construction companies, the main causes that respondents discussed include the economic losses from the company, delays at the beginning of new projects, and the lack of financial support from the government. Regarding the effects of financial solvency issues, the respondents reported the company's lack of liquidity, losses of company income, difficulties accessing bank loans to develop construction projects, and the losses of income for construction workers. Interestingly, although the impacts of financial solvency issues were focused on the company level, the impacts on construction workers were also identified. These results suggest that the impacts of COVID-19 on construction projects may have cascading impacts on construction projects to which we also need to pay attention. These results may be pointing out that the disruptions and consequences of COVID-19 on construction projects might be much more complex than previously discussed.

When it comes to the technical performance of workers, this impact was caused by the difficulty to find qualified construction workers, hiring of less qualified construction workers, reduction of working space and working hours, and communication problems regarding COVID-19 protocols. These results are consistent with studies that identified the hiring of qualified workers as a challenge for construction companies during the pandemic (e.g., [11]). However, it is contrary to what other researchers have stated by identifying the current context as an opportunity due to the expected surplus of skilled workers in the construction market [14]. We suspect that one of the main reasons for workers being unwilling to work through the current pandemic context is the uncertainty related to their safety status when visiting a construction site, which is similar to what researchers have previously discussed (e.g., [52-54]). Regarding the consequences of construction workers' technical performance, these included replacement of subcontractors and reduction of construction workers. Notably, the literature has identified the nonperformance among subcontractors as a consequence of COVID-19 in the construction sector [14]; however, it was not related to construction workers' technical performance.

Interestingly, when looking at the construction stakeholders, respondents reported that engineers and managers in charge of managing construction projects and construction workers have been the most affected by the COVID-19 pandemic. These findings support the completion of the objective 2 presented in this study.

From the result of Figures 2 and 3, four associations of COVID-19 impacts and stakeholders are identified whose distance is associated with three underlying dimensions. In principle, the distance between the association (A) of subcontractors and suppliers and (B) the Construction company and owners is notorious. In both cases, both the causes and the effects of COVID-19 could be associated with a common interpretation. In the first, (A) subcontractors and suppliers and their impacts/causes of COVID are differentiated from the rest of stakeholders due to their externality regarding the development of the project, i.e., their sense of affiliation to the projects is different from the rest that is centered on zero for Dimension 1. Second (B), the construction company, the owners, and their impacts and causes are differentiated from the rest due to their influence on decision making, i.e., its decisions imply causes of financial solvency impact, unlike the rest that is centered on zero for Dimension 3; and otherwise also receive the effects of financial solvency and on the resilience of the industry. In particular, public agencies are part of the decision-making group (Figure $3 b$ ) and affect the resilience and financial solvency of the industry (e.g., delay in payments for the progress of works or limit the continuity of work). This approach is consistent with the statements of $[16,17]$ regarding the initiatives and decision-making capacity of companies and public agencies to undertake challenging construction projects and self-required safety protocols on site, respectively. On the other hand, there is a distance between $(C)$ the project team and (D) the construction workers with less variability but still noticeable difference.

On the other hand, in Figures $2 a$ and $3 a$, there is a distance between the project team (C) and the construction workers (D), with less variability but still a notable difference. In both cases, the difference depends on the interpretation of Dimension 2 according to 
the categories of cause (project dependency) or effect (transversely of effects). In this way, the project team (C) is associated with greater dependence and management of the causes; likewise, the effects that fall on him (C) are transversal to all members. The causes and effects associated with $\mathrm{C}$ are productivity, work stoppages, the health and safety protocol, and only the effect on industrial resilience. These findings align with the studies by [17] that highlight the need for construction managers' new knowledge and skills to protect safety against the spread of COVID-19. In addition, Ref. [55] visualize the need for technological support to project management teams, to maintain productivity, reduce delays and withstand the pandemic, based on the BIM methodology. Similarly, and according to the results in Dimension 2 construction workers (D) are involved in causes that are less conditioned to the project's development and more difficult to control; likewise, the effects that fall on workers (D) have a more individual effect than those that fall on the project team. The causes and effects associated with association D are: unemployment, quarantine, mental health, and mobility difficulties. In this sense, research by $[4,10,54]$ identify the vulnerability and contagion risks of construction workers and their families in the face of the spread of COVID-19. Among the limitations, they point to are problems of accessibility, availability, panic, and the difficulty of adapting to new working conditions. Between associations C and D, there is the particular case of Public Agencies. In this case, Figure 2a associates Public Agencies with construction workers (D). Indeed, Public Agencies in the context of a pandemic cause impacts through slowed down public administration processes, mobility difficulties, and quarantine control. On the contrary, in Figure $3 a$ the public agencies attract the effects related to the flexibility for the reception of the works, the closing of projects, or being an intermediary in the negotiation process (category of resilience in the industry).

According to the finding of these four associations (A, B, C, and D), it would be possible to reflect on public policies efficiently designed to face the impacts of COVID-19. In other words, measures that support the construction company are unlikely to have the same impact on smaller suppliers and subcontractors. Similarly, targeted support for workers meets individual needs, which may not impact infrastructure development equally. However, improving the capabilities of the project team could affect all internal members across the board. These situations constitute potential hypotheses to take into account in future lines of development. These findings give response to objective 3 presented in this study.

\section{Conclusions}

This study explored the impacts of COVID-19 among multiple construction stakeholders. Namely, this study had three objectives: identify the impacts of COVID-19 on construction projects among multiple stakeholders; how the cause and effect of such impacts vary among stakeholders; and identify whether there is an association between impacts due to COVID-19 and construction stakeholders. Data were collected through semi-structured interviews and enabled qualitative content analysis and correspondence analysis. Fifteen categories of impacts were identified on construction projects due to COVID-19 among multiple stakeholders. The causes and effects of impacts due to COVID19 varied among construction stakeholders, yet most of impacts were related to construction workers and engineers and managers. Moreover, through the correspondence analysis, we discovered four associations determined by the suppliers and subcontractors, the project team, the owner and construction company, and the construction workers. These associations are interpreted through three dimensions: (1) the degree of membership, (2) the power in decision-making, and (3) the dependence-control of the causes and transversely of the effects.

This study contributes to the existing literature about COVID-19 and construction projects by identifying impacts due to COVID-19 and stakeholders affected by such impacts and how these impacts' relationships interacted among them. In practicality, supported by the contribution of this study, stakeholders can establish practices to deal with the impacts 
of COVID-19 so the consequences of COVID-19 among construction stakeholders may be minimized. For instance, proposing strategies that specifically target internal and external causes that are beyond the control of construction stakeholders. Similarly, by developing strategies to specifically address the consequences of impacts of COVID-19 that affect stakeholders at the individual level (i.e., construction workers).

Future research should expand on our exploratory findings based on qualitative research with quantitative research, for instance, by collecting data through a survey to assess the impacts on construction stakeholders so the findings may be considered statistically representative of the population. Moreover, future studies might focus on the influence that the vaccination campaigns have had on the impacts of COVID-19 on construction projects. It is expected that the vaccination of workers may be encouraging the return to pre-pandemic operations, however, limited is known about this situation. Ultimately, future studies should focus on strategies to mitigate the impacts of COVID-19 on the construction sector. In so doing, the level of effectiveness of strategies to mitigate the impacts of COVID-19 can be evaluated by decision-makers.

Author Contributions: Conceptualization, F.A. and L.S.; methodology, F.A. and L.S.; validation, F.A. and L.S.; formal analysis, F.A. and L.S.; investigation, F.A. and L.S.; data curation, F.A. and L.S.; writing-original draft preparation, F.A. and L.S.; writing—review and editing, F.A. and L.S. All authors have read and agreed to the published version of the manuscript.

Funding: This research was funded by Agencia Nacional de Investigación y Desarrollo (ANID) of Government of Chile under the Fondo Nacional de Desarrollo Científico y Tecnológico (FONDECYT-INI), grant number 11190501.

Institutional Review Board Statement: The study was conducted according to the guidelines of the Declaration of Helsinki and approved by the Ethics Committee of the University of La Frontera (Protocol 094/19 approved 9 October 2019).

Informed Consent Statement: Informed consent was obtained from all subjects involved in the study.

Data Availability Statement: Data is available under request to the corresponding author.

Acknowledgments: The authors are grateful for the participation of the 40 interviewed professionals of Chilean construction companies and the integrated work by the research groups of the Civil Engineering Departments of the University of La Frontera (GIPS) and of the Federico Santa Maria Technical University.

Conflicts of Interest: The authors declare no conflict of interest.

\section{References}

1. Amankwah-Amoah, J. Stepping up and stepping out of COVID-19: New challenges for environmental sustainability policies in the global airline industry. J. Clean. Prod. 2020, 271, 123000. [CrossRef]

2. Ranjbari, M.; Esfandabadi, Z.S.; Zanetti, M.C.; Scagnelli, S.D.; Siebers, P.-O.; Aghbashlo, M.; Peng, W.; Quatraro, F.; Tabatabaei, M. Three pillars of sustainability in the wake of COVID-19: A systematic review and future research agenda for sustainable development. J. Clean. Prod. 2021, 297, 126660. [CrossRef]

3. Severo, E.A.; De Guimarães, J.C.F.; Dellarmelin, M.L. Impact of the COVID-19 pandemic on environmental awareness, sustainable consumption and social responsibility: Evidence from generations in Brazil and Portugal. J. Clean. Prod. 2021, $286,124947$. [CrossRef]

4. Araya, F. Modeling the spread of COVID-19 on construction workers: An agent-based approach. Saf. Sci. 2021, 133, 105022. [CrossRef]

5. Ebekozien, A.; Aigbavboa, C. COVID-19 recovery for the Nigerian construction sites: The role of the fourth industrial revolution technologies. Sustain. Cities Soc. 2021, 69, 102803. [CrossRef]

6. Amoah, C.; Simpeh, F. Implementation challenges of COVID-19 safety measures at construction sites in South Africa. J. Facil. Manag. 2021, 19, 111-128. [CrossRef]

7. Casady, C.B.; Baxter, D. Pandemics, public-private partnerships (PPPs), and force majeure I COVID-19 expectations and implications. Constr. Manag. Econ. 2020, 38, 1077-1085. [CrossRef]

8. ENR. AGC Says 75\% of Contractors Had Project Canceled or Postponed Due to Coronavirus. 2020. Available online: https: / / www.enr.com/articles/50527-agc-says-75-of-contractors-had-project-canceled-or-postponed-due-to-coronavirus (accessed on 17 February 2021). 
9. Moufid, I.; Naciri, S.; El Moussaoui, H.; Lamhamdi, T.; El Markhi, H. Power Loss Minimization Using the Integration of DGs And Reconfiguration of Distribution System: Applied on Real Distribution Feeder of Urbain Areas of Kenitra City in Morroco. Adv. Sci. Technol. Eng. Syst. J. 2020, 5, 74-79. [CrossRef]

10. Wang, Z.; Liu, Z.; Liu, J. Risk Identification and Responses of Tunnel Construction Management during the COVID-19 Pandemic. Adv. Civ. Eng. 2020, 2020, 1-10. [CrossRef]

11. Assaad, R.; El-Adaway, I.H. Guidelines for Responding to COVID-19 Pandemic: Best Practices, Impacts, and Future Research Directions. J. Manag. Eng. 2021, 37, 06021001. [CrossRef]

12. Wang, Q.; Zhang, F. What does the China's economic recovery after COVID-19 pandemic mean for the economic growth and energy consumption of other countries? J. Clean. Prod. 2021, 295, 126265. [CrossRef]

13. Daniels, W.; Griffith, M.; Shreve, R. The Coronavirus Effect on Construction Projects. 2020. Available online: https://www. jdsupra.com/legalnews/the-coronavirus-effect-on-construction-13000/ (accessed on 5 April 2021).

14. Alsharef, A.; Banerjee, S.; Uddin, S.; Albert, A.; Jaselskis, E. Early Impacts of the COVID-19 Pandemic on the United States Construction Industry. Int. J. Environ. Res. Public Health 2021, 18, 1559. [CrossRef]

15. Pirzadeh, P.; Lingard, H. Working from Home during the COVID-19 Pandemic: Health and Well-Being of Project-Based Construction Workers. J. Constr. Eng. Manag. 2021, 147, 04021048. [CrossRef]

16. Simpeh, F.; Amoah, C. Assessment of measures instituted to curb the spread of COVID-19 on construction site. Int. J. Constr. Manag. 2021, 11, 1-19. [CrossRef]

17. Zheng, L.; Chen, K.; Ma, L. Knowledge, Attitudes, and Practices Toward COVID-19 Among Construction Industry Practitioners in China. Front. Public Health 2021, 8, 599769. [CrossRef] [PubMed]

18. Bal, M.; Bryde, D.; Fearon, D.; Ochieng, E. Stakeholder Engagement: Achieving Sustainability in the Construction Sector. Sustainability 2013, 5, 695-710. [CrossRef]

19. Chinyio, E.; Olomolaiye, P. (Eds.) Construction Stakeholder Management; John Wiley \& Sons: Hoboken, NJ, USA, 2009.

20. Li, T.H.Y.; Ng, S.T.; Skitmore, M. Modeling Multi-Stakeholder Multi-Objective Decisions during Public Participation in Major Infrastructure and Construction Projects: A Decision Rule Approach. J. Constr. Eng. Manag. 2016, 142, 04015087. [CrossRef]

21. King, S.S.; Rahman, R.A.; Fauzi, M.A.; Haron, A.T. Mechanisms for addressing the impact of COVID-19 on infrastructure projects. IOP Conf. Ser. Earth Environ. Sci. 2021, 682, 012047. [CrossRef]

22. Gamil, Y.; Alhagar, A. The Impact of Pandemic Crisis on the Survival of Construction Industry: A Case of COVID-19. Mediterr. J. Soc. Sci. 2020, 11, 122. [CrossRef]

23. Araya, F.; Sierra, L.; Basualto, D. Identifying the Impacts of COVID-19 on Chilean Construction Projects. In Proceedings of the Annual Conference of Canadian Society of Civil Engineers, Niagara Falls, ON, Canada, 26-29 May 2021.

24. Stiles, S.; Golightly, D.; Ryan, B. Impact of COVID-19 on health and safety in the construction sector. Hum. Factors Ergon. Manuf. 2021, 31, 425-437. [CrossRef]

25. Zamani, S.H.; Rahman, R.A.; Fauzi, M.A.; Yusof, L.M. Effect of COVID-19 on building construction projects: Impact and response mechanisms. IOP Conf. Ser. Earth Environ. Sci. 2021, 682, 012049. [CrossRef]

26. Reid, R.L. Accelerating Through Adversity. Civ. Eng. Mag. Arch. 2020, 90, 40-47. [CrossRef]

27. Kamal, M.M. The triple-edged sword of COVID-19: Understanding the use of digital technologies and the impact of productive, disruptive, and destructive nature of the pandemic. Inf. Syst. Manag. 2020, 37, 310-317. [CrossRef]

28. Pamidimukkala, A.; Kermanshachi, S.; Jahan Nipa, T. Impacts of COVID-19 on Health and Safety of Workforce in Construction Industry. In Proceedings of the International Conference on Transportation and Development, Seattle, WA, USA, 8-10 June 2021; pp. 418-430.

29. Raoufi, M.; Fayek, A.R. Identifying Actions to Control and Mitigate the Effects of the COVID-19 Pandemic on Construction Organizations: Preliminary Findings. Public Work. Manag. Policy 2021, 26, 47-55. [CrossRef]

30. Biernacki, P.; Waldorf, D. Snowball Sampling: Problems and Techniques of Chain Referral Sampling. Sociol. Methods Res. 1981, 10, 141-163. [CrossRef]

31. Noy, C. Sampling Knowledge: The Hermeneutics of Snowball Sampling in Qualitative Research. Int. J. Soc. Res. Methodol. 2008, 11, 327-344. [CrossRef]

32. Lowe, A.; Norris, A.C.; Farris, A.J.; Babbage, D.R. Quantifying Thematic Saturation in Qualitative Data Analysis. Field Methods 2018, 30, 191-207. [CrossRef]

33. Dodds, S.; Hess, A.C. Adapting research methodology during COVID-19: Lessons for transformative service research. J. Serv. Manag. 2020, 32, 203-217. [CrossRef]

34. Saldaña, J. The Coding Manual for Qualitative Researchers; Sage: New York, NY, USA, 2021.

35. Bryman, A. Social Research Methods (Fourth); Oxford University Press: Oxford, UK, 2012.

36. Krippendorff, K. Content Analysis: An Introduction to Its Methodology; SAGE Publications Inc.: Los Angeles, CA, USA, 2004.

37. Wicks, D. The Coding Manual for Qualitative Researchers (3rd edition). Qual. Res. Organ. Manag. Int. J. 2017, 12, 169-170. [CrossRef]

38. Sierra, L.A.; Yepes, V.; Pellicer, E. A review of multi-criteria assessment of the social sustainability of infrastructures. J. Clean. Prod. 2018, 187, 496-513. [CrossRef]

39. Carnevalli, J.A.; Miguel, P.C. Review, analysis and classification of the literature on QFD—Types of research, difficulties and benefits. Int. J. Prod. Econ. 2008, 114, 737-754. [CrossRef] 
40. Greenacre, M. Correspondence Analysis in Practice; Chapman \& Hall/CRC: Boca Raton, FL, USA, 2007.

41. Greenacre, M.J. Theory and Applications of Correspondence Analysis; Academic Press: London, UK, 1984.

42. Wright, T.S.; Allen, M. Garfinkeling. The SAGE Encyclopedia of Communication Research Methods; Sage: New York, NY, USA, 2017; Volume 1, p. 275.

43. Bendixen, M. A Practical Guide to the Use of Correspondence Analysis in Marketing Research. Marketing Bulletin 14. 2003. Available online: http://marketing-bulletin.massey.ac.nz/V14/MB_V14_T2_Bendixen.pdf (accessed on 23 August 2021).

44. Penadés-Plà, V.; García-Segura, T.; Martí, J.V.; Yepes, V. A Review of Multi-Criteria Decision-Making Methods Applied to the Sustainable Bridge Design. Sustainability 2016, 8, 1295. [CrossRef]

45. Prouty, C.; Koenig, E.S.; Wells, E.C.; Zarger, R.K.; Zhang, Q. Rapid assessment framework for modeling stakeholder involvement in infrastructure development. Sustain. Cities Soc. 2017, 29, 130-138. [CrossRef]

46. Batel, S.; Devine-Wright, P. A critical and empirical analysis of the national-local 'gap' in public responses to large-scale energy infrastructures. J. Environ. Plan. Manag. 2014, 58, 1076-1095. [CrossRef]

47. CChC. Protocol of Preventive Actions against COVID-19. Available online: https://coronavirus.cchc.cl/uploads/archivos/ Protocolo-de-acciones-preventivas-covid_4.0_actualizado_al_24082020-Vf_.pdf (accessed on 26 May 2021).

48. CChC. Report about Macroeconomy and Construction, MACh56. Available online: https://cchc.cl/uploads/archivos/archivos/ mach-56.pdf (accessed on 26 May 2021).

49. CChC. Report about Macroeconomy and Construction, MACh55. Available online: https://cchc.cl/uploads/archivos/archivos/ informe-mach55-enero-2021.pdf (accessed on 26 May 2021).

50. CChC. Report about Macroeconomy and Construction, MACh53. Available online: https://cchc.cl/uploads/archivos/archivos/ informe-mach53-julio-2020.pdf (accessed on 26 May 2021).

51. Araya, F. Challenges faced by women in construction: A state-of-the-art review and discusion in the Chilean context. Rev. Ing. Constr. 2021, 36, 14-20. [CrossRef]

52. Hatoum, M.B.; Faisal, A.; Nassereddine, H.; Sarvari, H. Analysis of COVID-19 Concerns Raised by the Construction Workforce and Development of Mitigation Practices. Front. Built Environ. 2021, 7. [CrossRef]

53. Choi, S.D.; Staley, J. Safety and Health Implications of COVID-19 on the United States Construction Industry. Ind. Syst. Eng. Rev. 2021, 9. [CrossRef]

54. Araya, F. Modeling working shifts in construction projects using an agent-based approach to minimize the spread of COVID-19. J. Build. Eng. 2021, 41, 102413. [CrossRef]

55. Pavón, R.; Alvarez, A.; Alberti, M. Possibilities of BIM-FM for the Management of COVID in Public Buildings. Sustainability 2020, 12, 9974. [CrossRef] 